\title{
Catalysis using colloidal-supported gold-based nanoparticles
}

\author{
Nikolaos Dimitratos • Ceri Hammond $\cdot$ \\ Christopher J. Kiely • Graham J. Hutchings
}

Received: 7 February 2014/ Accepted: 2 April 2014/Published online: 27 April 2014

(C) The Author(s) 2014. This article is published with open access at Springerlink.com

\begin{abstract}
The discovery of novel materials that can be active, selective and stable catalysts for the efficient transformation of organic molecules to useful products is of high importance. In recent years, there has been significant interest in the utilisation of supported gold-based nanoparticles that can be effective catalysts for a broad range of chemical processes. In this paper, we describe and discuss the utilisation of gold-based nanoparticles as efficient catalysts for a range of important reactions, with particular emphasis placed on our team recent research.
\end{abstract}

Keywords Gold catalysis - Nanoparticles · Alkane activation $\cdot$ Alcohol oxidation

\section{Introduction}

For a long period, gold was considered to be one of the least catalytically useful materials. Gold is unique among the metallic elements because of its resistance to oxidation and corrosion; its well-known history of usage in coinage and in jewellery perfectly illustrates this chemical nobility [1]. However, this perception has changed dramatically over recent years, following the seminal discoveries of

\footnotetext{
N. Dimitratos $(\bowtie) \cdot$ C. Hammond · G. J. Hutchings

School of Chemistry, Cardiff University, Main Building,

Park Place, Cardiff CF10 3AT, UK

e-mail: sacnd1@ cardiff.ac.uk

G. J. Hutchings

e-mail: hutch@cardiff.ac.uk

\section{J. Kiely}

Center for Advanced Materials and Nanotechnology, Lehigh University, 5 East Packer Avenue, Bethlehem, PA 18015-3195, USA
}

Bond, Hutchings and Haruta, who identified that finely divided gold particles were particularly active catalysts for the hydrogenation of olefins [2], the hydrochlorination of ethyne to vinyl chloride [3] and the low temperature oxidation of CO [4], respectively. From these studies, it was identified that when Au is present as very small particles, with a mean diameter below $10 \mathrm{~nm}$, it becomes surprisingly catalytically active, especially at low temperatures. After these important discoveries, many research groups in academia and industry have focused their research upon exploring the catalytic performance of Au catalysts for a wide range of oxidation and hydrogenation reactions $[5,6]$. New discoveries have been reported since that period, and novel, designed supported gold nanoparticles have shown to be extremely effective catalysts for the oxidation of $\mathrm{CO}$ [7-11], the selective oxidation of alcohols and polyols [12, 13], the epoxidation of olefins [14, 15], the hydrochlorination of ethyne [16], the selective hydrogenation of unsaturated carbonyl and nitro groups [17], and the direct synthesis of hydrogen peroxide from molecular hydrogen and oxygen [18]. Whilst these monometallic Au nanoparticles have been shown to be effective redox catalysts, we have shown over the last decade that using bimetallic catalysts, such as Au-Pd catalysts, a significant improvement in terms of catalytic reactivity and stability for a range of reactions, such as the oxidation of alcohols [19] and hydrogen peroxide synthesis [20-22], could be observed. In this paper we review some of our recent work focusing on the synthesis of $\mathrm{Au}-\mathrm{Pd}, \mathrm{Au}-\mathrm{Pt}$ and $\mathrm{Au}-\mathrm{Pd}-\mathrm{Pt}$ alloy and core-shell nanoparticles with colloidal methods, and their catalytic performance in a range of reactions, namely alkane activation (toluene and methane oxidation) and the oxidation of alcohols and polyols using molecular oxygen or hydrogen peroxide/tert-butyl hydroperoxide as green oxidants. These two reactions have a very broad 
interest and remain great challenges yet to be solved by the academic and industrial communities. In the case of alcohol and polyol oxidation, control of the selectivity to the desired product (aldehyde/ketone versus carboxylic acid or ester) is the key. Conversely, in the case of alkane oxidation the key challenge is to enhance activity at mild conditions, avoiding harsh reaction conditions and corrosive solvent systems, whilst concurrently controlling selectivity towards the desired product. This paper reviews some of the essential aspects of various bimetallic and trimetallic catalysts prepared using a colloidal method for these reactions.

\section{Case I. Selective oxidation of alcohols and polyols}

A variety of important industrial chemicals can be obtained by the selective oxidation of alcohols and polyols into the corresponding carbonylic or carboxylic derivatives through the use of heterogeneous catalysts [23, 24]. In our studies, we have primarily used benzyl alcohol and glycerol as model substrates for studying the catalytic performance of supported Au-based nanoparticles for alcohol/polyol oxidation. The methodologies for synthesising Au-based nanoparticles are primarily based on colloidal methods, and to a lesser extent impregnation methods. The advantages of colloidal methods rely on the fact that metal nanoparticles with a narrow particle size distribution and with a specific morphology can be synthesised. Nano-sized metal colloids are usually synthesised by an in situ reduction method from a suitable metal precursor, such as chemical reduction (with $\mathrm{NaBH}_{4}$ or alcohol), photoreduction, electrochemical reduction or thermal decomposition [25]. Small molecular ligands, surfactants and polymers have been used to stabilise the so-formed metallic colloids. In some cases, metal colloids are stable over long periods even without coagulation in a solvent. However, for prolonged stability in a sol state, and for obtaining a uniform, controlled particle size, use of a stabilising ligand is essential. Typically, polymers such as polyvinyl alcohol and polyvinylpyrrolidone and various other surfactants have frequently been used. In the case of polymeric stabilisers, the typical stabilisation mechanism is based on steric stabilisation. However, electrostatic stabilisation is also possible through the utilisation of electrostatic stabilisers such as citrate. Our preferred method is based on steric stabilisation. The synthesis of colloidal metal nanoparticles typically requires (1) the use of inorganic metal precursors, such as $\mathrm{HAuCl}_{4}, \mathrm{PdCl}_{2}$ and $\mathrm{H}_{2} \mathrm{PtCl}_{6}$; (2) the use of $\mathrm{H}_{2} \mathrm{O}$ as solvent; (3) dilute aqueous solutions of polyvinyl alcohol (PVA) as stabiliser and $\mathrm{NaBH}_{4}$ as the reducing agent. For the synthesis of Au-based colloids, the first step involves the dissolution of the desired metal precursors in aqueous solution, followed by the addition of the desired amount of PVA. By adding $\mathrm{NaBH}_{4}$ as the reducing agent, the formation of a colloidal solution is subsequently achieved. The final step involves the immobilisation of the Au-based colloids onto the desired heterogeneous support, such as carbon, $\mathrm{TiO}_{2}$ or other metal oxide supports [26]. The synthesis of alloyed or core-shell structures is possible by modifying the reduction step. In the case of forming alloy nanoparticles, a simultaneous reduction process should be followed, whereas in the case of core-shell structures a sequential reduction protocol is essential.

The catalytic performance of supported $\mathrm{Au}-\mathrm{Pd}$ nanoparticles with alloy and core-shell structures synthesised by colloidal methods was carried out for the aerobic oxidation of benzyl alcohol. High catalytic efficiency of Au-Pd catalysts was demonstrated with very high TOFs (turnover frequencies) $\left(40,000 \mathrm{~h}^{-1}\right)$ at mild reaction conditions $\left(120{ }^{\circ} \mathrm{C}, \mathrm{PO}_{2}=10\right.$ bar) when random $\mathrm{Au}-\mathrm{Pd}$ alloy nanoparticles were used (Table 1) [26, 27]. Extensive STEMXDS and XPS studies were performed to characterise the synthesised materials. These studies showed the presence of random homogeneous alloys with metallic oxidation state for $\mathrm{Au}$ and the majority of $\mathrm{Pd}$ also present in metallic state. Higher activity of the supported $\mathrm{Au}-\mathrm{Pd}$ catalysts synthesised by the colloidal method instead of the impregnation

Table 1 Benzyl alcohol oxidation results after $2 \mathrm{~h}$ reaction for sol-immobilised $\mathrm{Au}-\mathrm{Pd}$ catalysts supported on $\mathrm{C}$ and $\mathrm{TiO}_{2}$ : the effect of the order of metal reduction in the preparation [27]

\begin{tabular}{|c|c|c|c|c|c|c|c|c|}
\hline \multirow[t]{2}{*}{ Catalyst } & \multirow[t]{2}{*}{ Conversion $(\%)$} & \multicolumn{6}{|c|}{ Selectivity (\%) } & \multirow[t]{2}{*}{$\mathrm{TOF} / \mathrm{h}^{-1 \mathrm{~b}}$} \\
\hline & & Benzene & Toluene & Benzaldehyde & Benzoic acid & Benzyl benzoate & Acetal & \\
\hline $1 \% \mathrm{Au}+\mathrm{Pd} / \mathrm{TiO}_{2}^{\mathrm{a}}$ & 61.2 & 0.5 & 26.7 & 69.2 & 1.7 & 1.9 & 0 & 15,400 \\
\hline $1 \% \mathrm{Pd}(\mathrm{Au}) / \mathrm{TiO}_{2}^{\mathrm{a}}$ & 57.8 & 0.2 & 18.1 & 77.1 & 1.8 & 2.8 & 0 & 19,300 \\
\hline $1 \% \mathrm{Au}(\mathrm{Pd}) / \mathrm{TiO}_{2}^{\mathrm{a}}$ & 48.7 & 0.4 & 23.0 & 72.3 & 1.9 & 2.5 & 0 & 17,400 \\
\hline $1 \% \mathrm{Au}+\mathrm{Pd} / \mathrm{C}^{\mathrm{a}}$ & 81.1 & 0.5 & 40.9 & 55.0 & 1.3 & 2.1 & 0.2 & 35,400 \\
\hline $1 \% \operatorname{Pd}(\mathrm{Au}) / \mathrm{C}^{\mathrm{a}}$ & 70.4 & 0.4 & 35.1 & 62.6 & 2.0 & 0.0 & 0 & 41,900 \\
\hline $1 \% \mathrm{Au}(\mathrm{Pd}) / \mathrm{C}^{\mathrm{a}}$ & 79.2 & 0.7 & 28.8 & 65.0 & 2.7 & 2.7 & 0 & 24,300 \\
\hline
\end{tabular}

${ }^{a}$ Reaction conditions: benzyl alcohol, $0.1 \mathrm{~g}$ of catalyst, $\mathrm{T}=120{ }^{\circ} \mathrm{C}, \mathrm{pO}_{2}=150$ psi, stirring rate $1,500 \mathrm{rpm}$

${ }^{\mathrm{b}}$ Calculation of TOF $\left(\mathrm{h}^{-1}\right)$ after $0.5 \mathrm{~h}$ of reaction. TOF numbers were calculated on the basis of total loading of metals 
Fig. 1 STEM-HAADF images of the starting colloids dispersed onto a continuous carbon thin film: a, b Au + Pd colloids; ce $\mathrm{Au}(\mathrm{Pd})$ colloids; and $\mathbf{f}-$ h $\mathrm{Pd}(\mathrm{Au})$ colloids. Circles indicate the presence of nanometer scale clusters of atoms; white arrows indicate the presence of Pd particles with complete Au coverage; yellow arrows indicate the presence of $\mathrm{Pd}$ particles with incomplete $\mathrm{Au}$ coverage; red arrows indicate the presence of Pd particles with no Au coverage; green arrows indicate the presence of bright atoms observed in the Pd shell indicating incorporation of $\mathrm{Au}$ atoms into the $\mathrm{Pd}$ shell region. Reprinted with permission from reference [28]. Copyright (2011) Royal Society of Chemistry
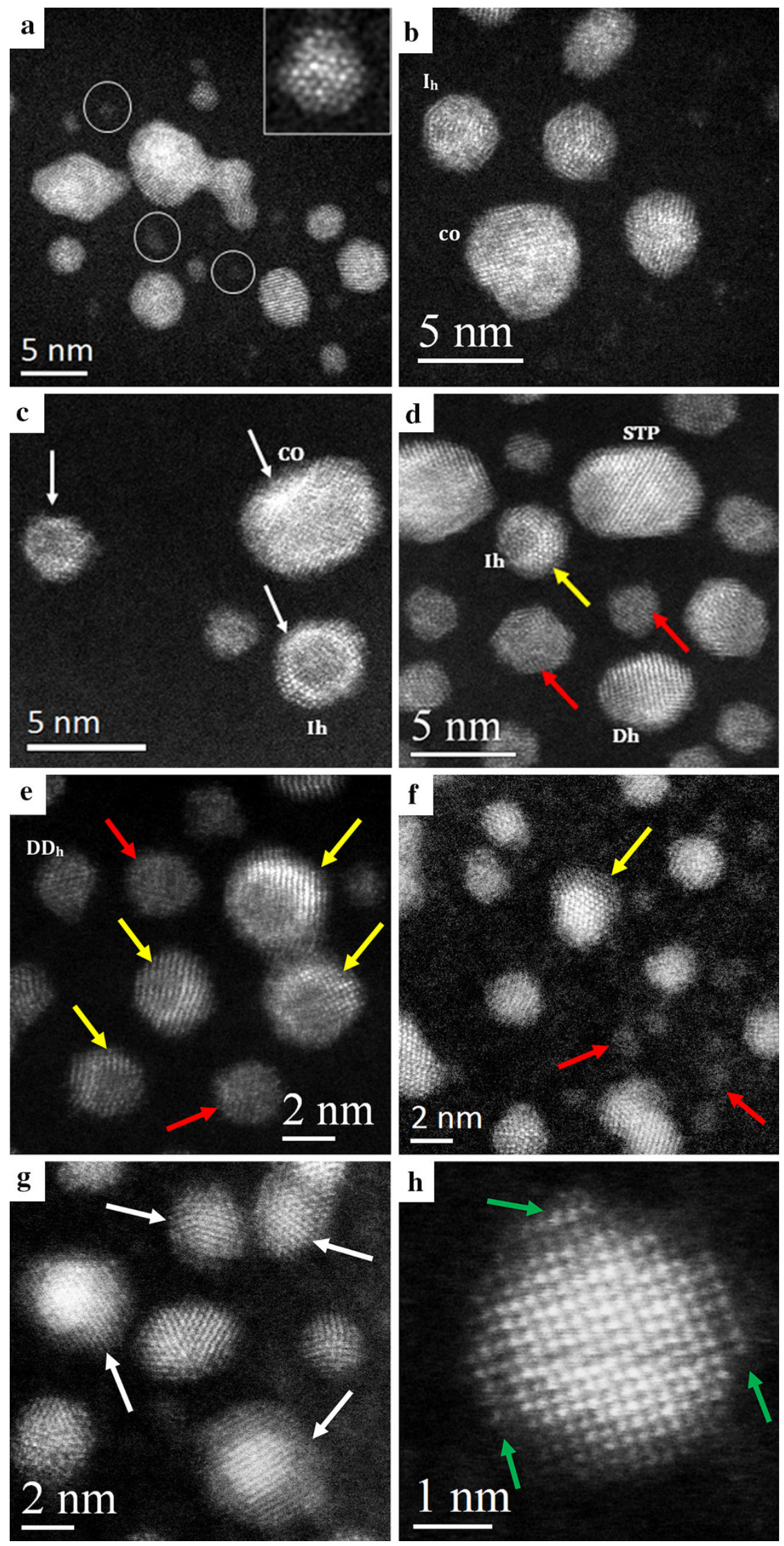

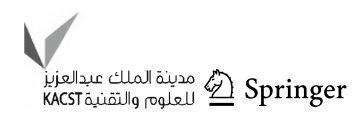


Table 2 Benzyl alcohol oxidation results at iso-conversion for sol-immobilised Au-Pd catalysts supported on $\mathrm{C}$ and $\mathrm{TiO}_{2}$ : the effect of the order of metal reduction in the preparation [27]

\begin{tabular}{|c|c|c|c|c|c|c|c|}
\hline \multirow[t]{2}{*}{ Catalyst } & \multirow[t]{2}{*}{ Conversion $(\%)$} & \multicolumn{6}{|c|}{ Selectivity (\%) } \\
\hline & & Benzene & Toluene & Benzaldehyde & Benzoic acid & Benzyl benzoate & Acetal \\
\hline $1 \% \mathrm{Au}+\mathrm{Pd} / \mathrm{TiO}_{2}^{\mathrm{a}}$ & 50 & 0.5 & 26.9 & 69.1 & 1.5 & 2.0 & 0 \\
\hline $1 \% \mathrm{Pd}(\mathrm{Au}) / \mathrm{TiO}_{2}^{\mathrm{a}}$ & 50 & 0.2 & 23.0 & 72.8 & 1.5 & 2.5 & 0 \\
\hline $1 \% \mathrm{Au}(\mathrm{Pd}) / \mathrm{TiO}_{2}^{\mathrm{a}}$ & 50 & 0.4 & 23.0 & 72.2 & 1.9 & 2.5 & 0 \\
\hline $1 \% \mathrm{Au}+\mathrm{Pd} / \mathrm{C}^{\mathrm{a}}$ & 50 & 0.3 & 44.0 & 51.3 & 1.7 & 2.7 & 0.1 \\
\hline $1 \% \operatorname{Pd}(\mathrm{Au}) / \mathrm{C}^{\mathrm{a}}$ & 50 & 0.3 & 41.6 & 54.6 & 1.6 & 1.8 & 0.1 \\
\hline $1 \% \mathrm{Au}(\mathrm{Pd}) / \mathrm{C}^{\mathrm{a}}$ & 50 & 0.6 & 38.9 & 57.1 & 1.6 & 1.7 & 0.1 \\
\hline
\end{tabular}

${ }^{a}$ Reaction conditions: benzyl alcohol, $0.1 \mathrm{~g}$ of catalyst, $\mathrm{T}=120{ }^{\circ} \mathrm{C}, \mathrm{pO}_{2}=150 \mathrm{psi}$

Table 3 Benzyl alcohol oxidation results after $2 \mathrm{~h}$ reaction with various Au-Pd-Pt catalysts supported on carbon prepared by the sol-immobilisation method [30]

\begin{tabular}{lllllll}
\hline Catalyst & Conversion $(\%)$ & \multicolumn{2}{l}{ Selectivity $(\%)$} & \\
\cline { 5 - 7 } & & Toluene & Benzaldehyde & Benzoic acid & Benzyl benzoate & TOF/h ${ }^{-1 b}$ \\
\hline $1 \mathrm{wt} \%(0.3 \mathrm{Au}+0.4 \mathrm{Pd}+0.3 \mathrm{Pt}) / \mathrm{C}^{\mathrm{a}}$ & 35.4 & 0.9 & 83.3 & 7.9 & 7.9 & 16,000 \\
$1 \mathrm{wt} \%(0.4 \mathrm{Au}+0.4 \mathrm{Pd}+0.2 \mathrm{Pt}) / \mathrm{C}^{\mathrm{a}}$ & 36.7 & 0.6 & 81.7 & 8.0 & 9.7 & 22,100 \\
$1 \mathrm{wt} \%(0.45 \mathrm{Au}+0.45 \mathrm{Pd}+0.1 \mathrm{Pt}) / \mathrm{C}^{\mathrm{a}}$ & 53.9 & 0.1 & 80.2 & 13.1 & 6.6 & 31,900 \\
\hline
\end{tabular}

${ }^{a}$ Reaction conditions: benzyl alcohol, $0.05 \mathrm{~g}$ of catalyst, $T=120^{\circ} \mathrm{C}, \mathrm{pO}_{2}=150 \mathrm{psi}$, stirring rate $1,500 \mathrm{rpm}$.

b Calculation of TOF $\left(\mathrm{h}^{-1}\right)$ value was done after $0.5 \mathrm{~h}$ of reaction, and was based on the total metal loading

$\mathbf{a}$

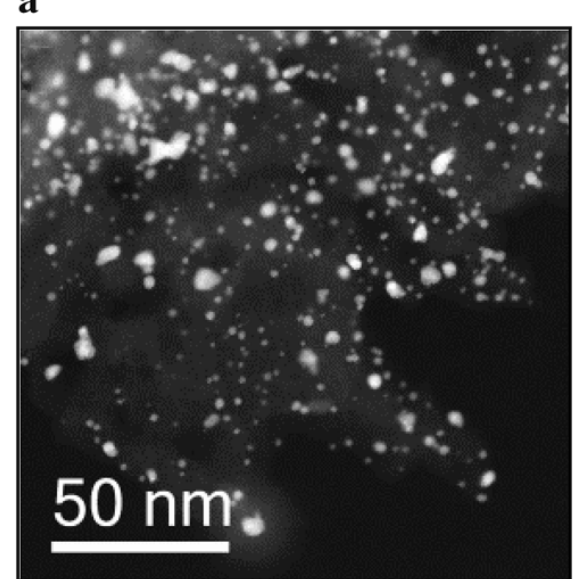

$1 \% 0.3 \mathrm{Au}+0.4 \mathrm{Pd}+0.3 \mathrm{Pt}) / \mathrm{C}$

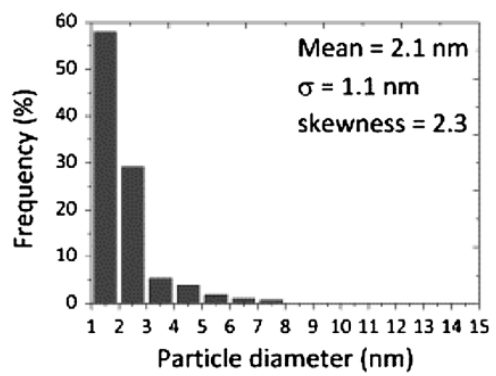

b

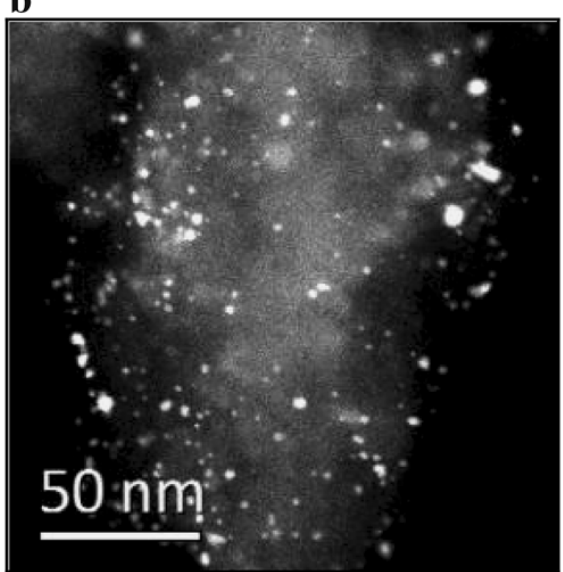

$1 \% 0.45 \mathrm{Au}+0.45 \mathrm{Pd}+0.1 \mathrm{Pt}) / \mathrm{C}$

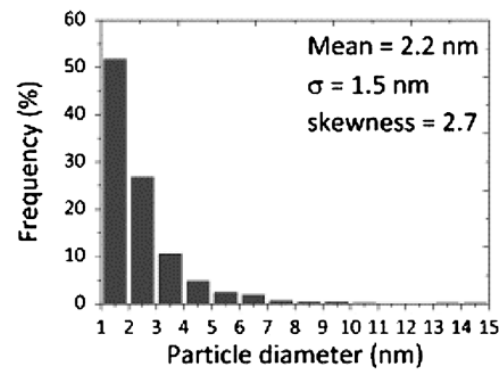

c

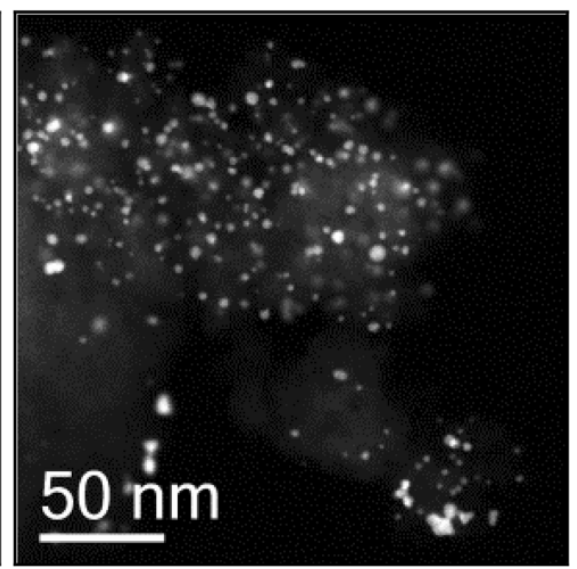

$1 \%(0.5 \mathrm{Au}+0.5 \mathrm{Pd}) / \mathrm{C}$

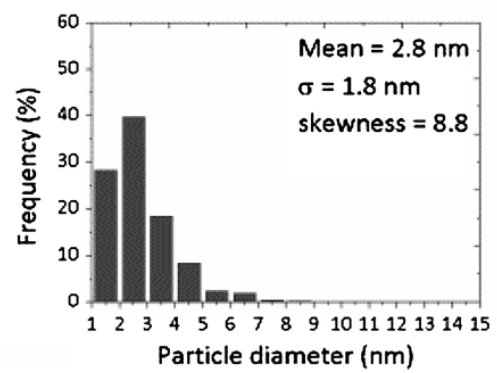

Fig. 2 Representative low-magnification STEM-HAADF images and corresponding particle size distributions of selected trimetallic, catalysts characterized in this study; namely; a $1 \mathrm{wt} \%(0.3 \mathrm{Au}-0.4$
Pd-0.3 Pt)/C; b 1 wt\% (0.45 Au-0.45 Pd-0.1 Pt)/C; c 1 wt\% (0.5 Au$0.5 \mathrm{Pd}$ )/C. Reprinted with permission from reference [30]. Copyright (2013) Royal Society of Chemistry 


\section{a}

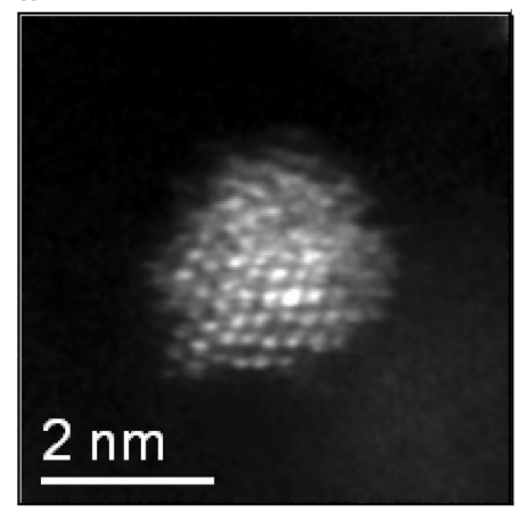

b

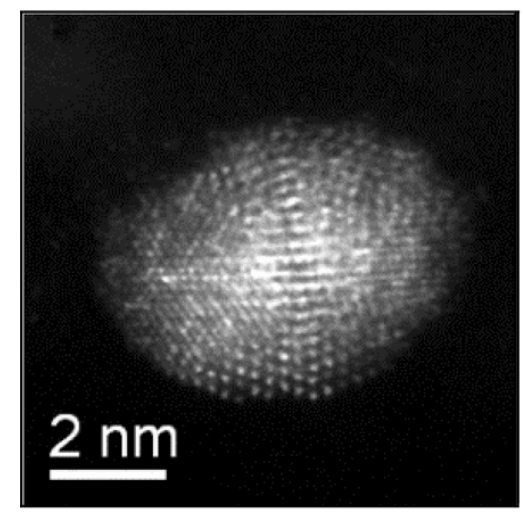

c

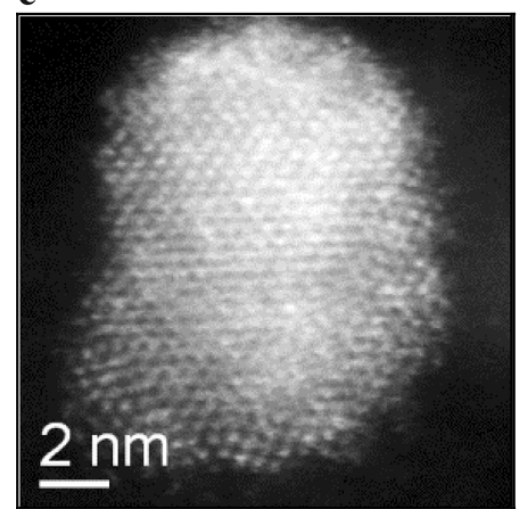

Fig. 3 High-magnification STEM-HAADF images and the corresponding X-ray energy dispersive spectra acquired from representative a $2 \mathrm{~nm}$, b $5 \mathrm{~nm}$ and c $10 \mathrm{~nm}$ particles in the sol-immobilised 1

method was observed, and it was mainly attributed to the significantly smaller average particle size, the narrower particle size distribution and the metallic oxidation state. In subsequent studies we investigated the catalytic performance of supported $\mathrm{Au}-\mathrm{Pd}$ nanoparticles with alloy and core-shell structures. As we described above, for the synthesis of supported bimetallic Au-Pd catalysts with coreshell structures, the preparation strategy was based on the sequential addition and reduction of each metal. The bimetallic sols were subsequently deposited onto the chosen
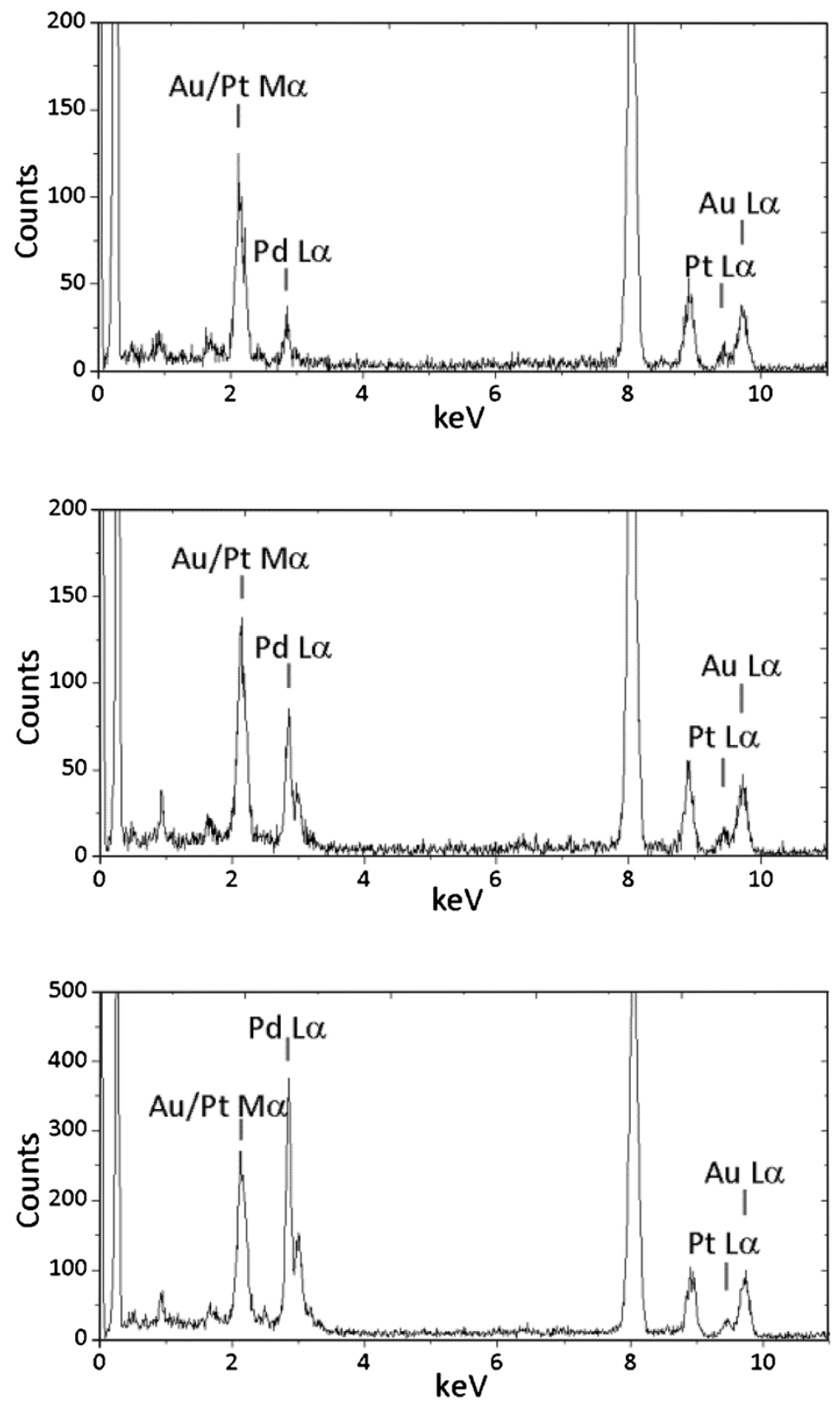

$\mathrm{wt} \%(0.45 \mathrm{Au}+0.45 \mathrm{Pd}+0.1 \mathrm{Pt}) / \mathrm{C}$ catalyst dried at $120^{\circ} \mathrm{C}$. Reprinted with permission from reference [30]. Copyright (2013) Royal Society of Chemistry

supports, carbon and titania. STEM-HAADF studies were performed to study the morphology of the synthesised colloids, and the formation of both alloyed and core-shell structures was shown (Fig. 1) [28]. It was found that the catalytic activity for the aerobic oxidation of benzyl alcohol could be carried out at mild conditions $\left(120^{\circ} \mathrm{C}\right.$, $\mathrm{PO}_{2}=10$ bar), and the order of metal addition has a marked effect on activity as well as selectivity (Table 1). The choice of support (carbon versus titania) was also shown to significantly affect both catalytic activity and the 


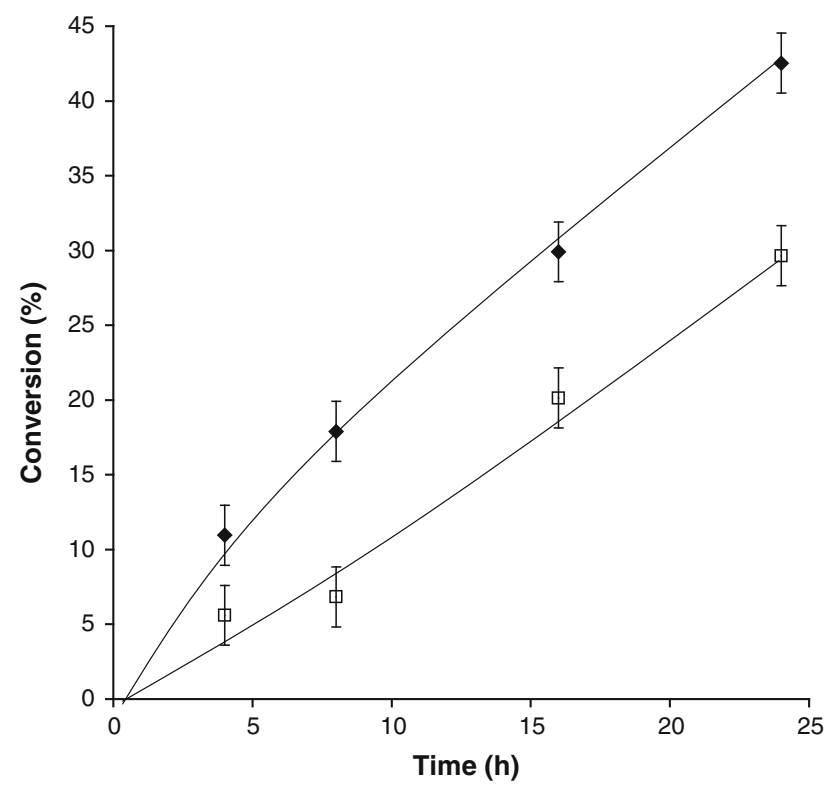

Fig. 4 Time-on-line data for selective oxidation of glycerol by $\mathrm{Au}-$ $\mathrm{Me} / \mathrm{MgO}$ catalysts, with $\mathrm{Me}=\mathrm{Pt}$ (filled diamond) or Pd (unfilled circle). Reaction conditions: 1:3 molar fraction Au:Me, total metal loading $1 \%$ by mass, water $(10 \mathrm{~mL}), 0.3 \mathrm{~mol} / \mathrm{L}$ glycerol, mole fraction of glycerol $/$ metal $=500, \mathrm{~T}=$ ambient, $\mathrm{pO}_{2}=300 \mathrm{kPa}$. Points represent the mean value obtained from ten reaction runs, and the error bars are defined by the range of these measurements. Reprinted with permission from reference [33]. Copyright (2011) Wiley-VCH

distribution of products (selectivity), with carbon-supported materials exhibiting both an increase of activity by a factor of 2 , and a lower selectivity to benzaldehyde at iso- conversion compared to the analogous $\mathrm{TiO}_{2}$-supported catalysts (Table 2). Mechanistic studies were performed for the oxidation of benzyl alcohol using an $\mathrm{Au}-\mathrm{Pd}$ alloy catalyst synthesised by colloidal method, and it was found that in the absence of oxygen benzyl alcohol was transformed into benzaldehyde and toluene at initial equal rates [29]. The introduction of oxygen significantly increased the rate of benzyl alcohol consumption and benzaldehyde production at the expense of toluene formation. It was found that at low partial pressures (below 3 bar of oxygen), the catalytic rate was dependent on oxygen, suggesting that oxygen can participate in the reaction pathway as an adsorbed species, whereas above 3 bar of oxygen the reaction is zero order in oxygen. The formation of benzaldehyde was found to be dependent upon the concentration of oxygen at the surface. Despite the fact that the high catalytic efficiency of supported $\mathrm{Au}-\mathrm{Pd}$ nanoparticles synthesised by colloidal method is evident, the challenge of achieving high selectivity to benzaldehyde remained still an issue. For tackling this challenge, either a low reaction temperature approach was chosen-resulting in a low turnover frequency (TOF)_or the conversion was kept at low levels (below $30 \%$ ). Another approach included the addition of a small amount of a third metal, such as $\mathrm{Pt}$, and the utilisation of supported trimetallic $\mathrm{Au}-\mathrm{Pd}-\mathrm{Pt}$ nanoparticles [30]. Using a simultaneous reduction method for the synthesis of preformed Au-Pd-Pt colloids, and by varying $\mathrm{Au}-\mathrm{Pd}-\mathrm{Pt}$ atomic ratios the catalytic performance of the synthesised supported $\mathrm{Au}-\mathrm{Pd}-\mathrm{Pt}$ nanoparticles was investigated. Variation of $\mathrm{Au}-\mathrm{Pd}-\mathrm{Pt}$ atomic ratios led to marked improvements in
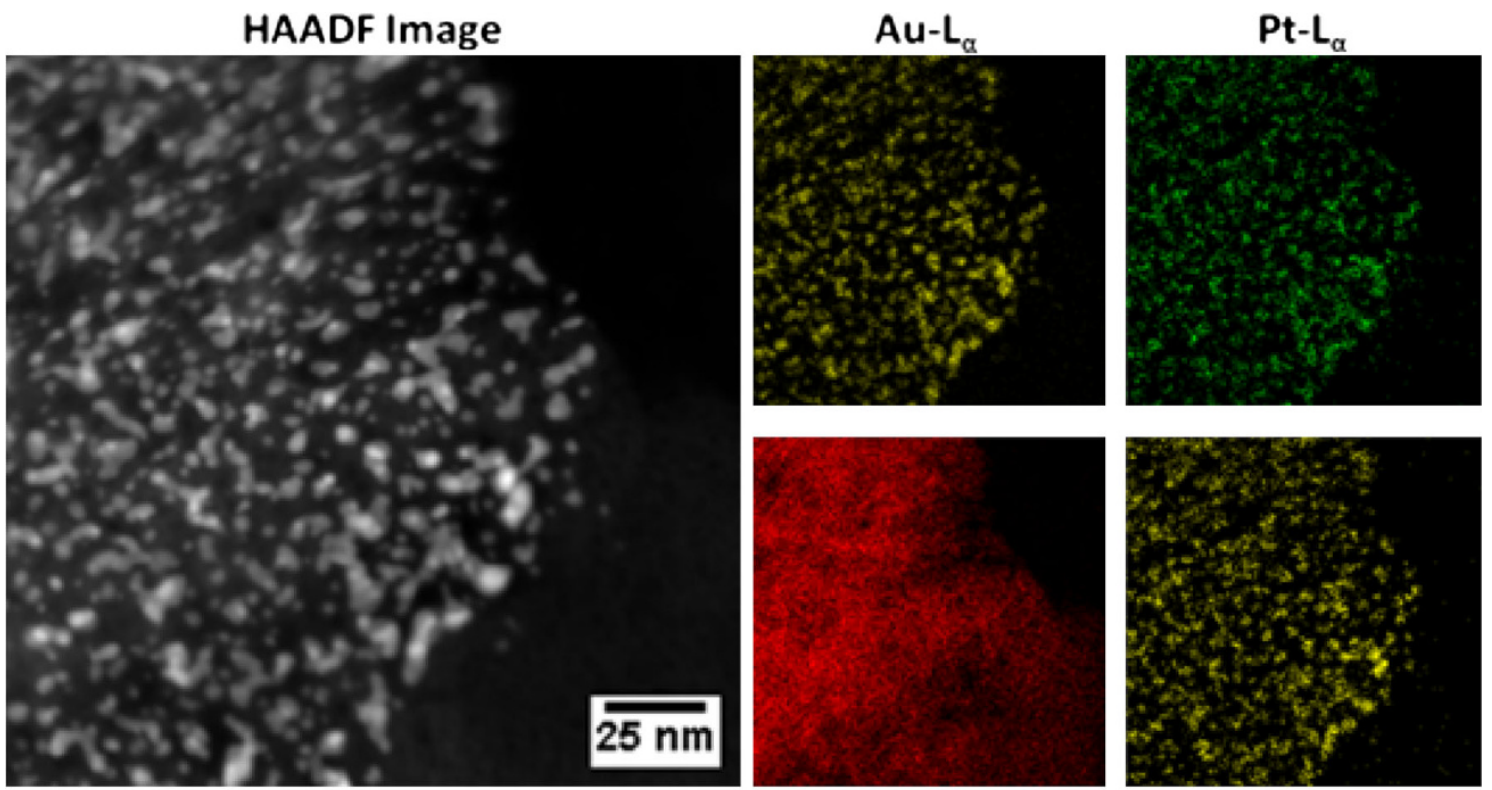

$\mathrm{Mg}-\mathrm{K}_{\alpha}$

Au- $\mathrm{M}_{\alpha} \& \mathrm{Pt}-\mathrm{M}_{\alpha}$

Fig. 5 HAADF image of the AuPt (1:1)/MgO catalyst (dried at $120^{\circ} \mathrm{C}$ ), along with the corresponding $\mathrm{Au}-\mathrm{L}_{\alpha}, \mathrm{Pt}-\mathrm{L}_{\alpha}$, Mg- $\mathrm{K}_{\alpha}$, and $(\mathrm{Au}-$ $\mathrm{M}_{\alpha}+\mathrm{Pt}-\mathrm{M}_{\alpha}$ ) elemental maps from the same area. Reprinted with permission from reference [33]. Copyright (2011) Wiley-VCH 


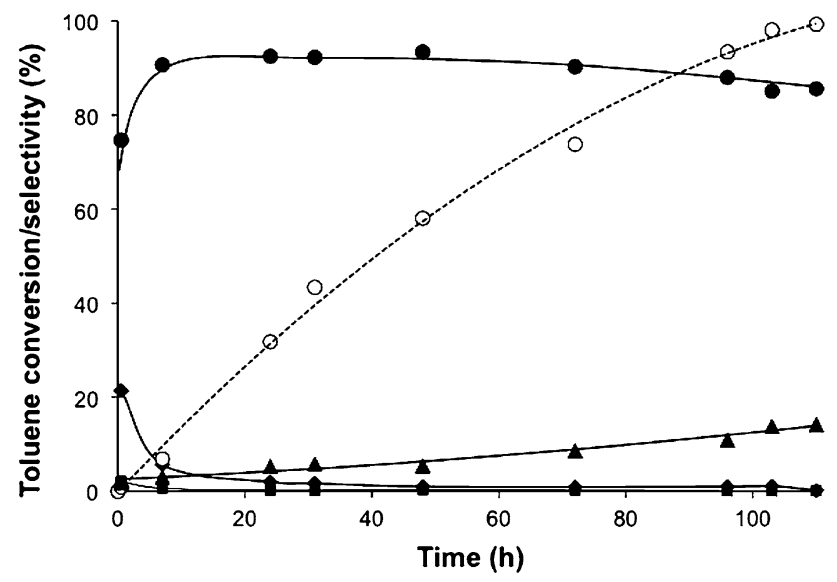

Fig. 6 Toluene conversion and selectivity to partial oxidation products. Reaction conditions: $160{ }^{\circ} \mathrm{C}, 0.1 \mathrm{MPa} p \mathrm{O}_{2}, 20 \mathrm{ml}$ toluene, $0.8 \mathrm{~g}$ of catalyst $(1 \mathrm{wt} \% \mathrm{AuPd} / \mathrm{C}$ prepared by sol immobilisation with a 1:1.85 Au/Pd ratio), toluene/metal molar ratio of 3,250 and reaction time: 110 h. Key: unfilled circle conversion filled square selectivity to benzyl alcohol,.. selectivity to benzaldehyde, closed up triangle selectivity to benzoic acid, filled circle selectivity to benzyl benzoate. Reprinted with permission from reference [34]. Copyright (2011) The American Association for the Advancement of Science

benzaldehyde selectivity (95\%) and significantly decreased the formation of toluene as by-product, whilst maintaining a high level of benzyl alcohol conversion (Table 3). STEMHAADF-XEDS studies showed that the mean particle size was around $2-3 \mathrm{~nm}$, and homogeneous trimetallic alloys were obtained (Fig. 2). However, depending on the size of the individual nanoparticles a clear size-dependent composition variation was found, with the smaller $(<2 \mathrm{~nm})$ particles found to be Pd-deficient, and particles larger than $10 \mathrm{~nm}$ observed to be Pd rich (Fig. 3). The beneficial effect of adding Pt atoms seems to be related to the role of $\mathrm{Pt}$ as electronic ( $\mathrm{Au}$ and $\mathrm{Pt}$ have higher electronegativity than $\mathrm{Pd}$, therefore can be accepted of electrons from Pd) or strain modifier to the Au-Pd nanoparticles, which reduces the capability of the Pd sites to be active for disproportionation reactions and therefore improving the selectivity to benzaldehyde. Therefore, the challenge of synthesising $\mathrm{Au}-\mathrm{Pd}-$ Pt nanoparticles with a controlled-size metal composition still remains.

Fig. 7 Reaction scheme for the oxidation of toluene to benzyl benzoate
Another organic compound that has recently attracted significant research interest is glycerol. The main reason is the following: glycerol, as a by-product from biodiesel production, is highly abundant and is readily available. As a waste material, its disposal via chemical fixation is highly favourable, and a large number of products can indeed be obtained from its chemical transformation. Nevertheless, whilst its high functionality leads to a number of potential products, particularly through oxidation, its high functionality demands exceptional control over reaction selectivity, and targeted selectivity to the desired products remains a significant challenge [31]. In previous studies, we have shown the efficient oxidative transformation of glycerol under alkaline conditions using supported $\mathrm{Au}-\mathrm{Pd}$ nanoparticles prepared by colloidal and impregnation methods [32]. A key challenge in the case of upgrading glycerol is the avoidance of alkaline conditions (without the use of $\mathrm{NaOH}$ as base), where the desired product will be the free carboxylic acid instead of the salt of acid. In our studies, Au-Pt nanoparticles were synthesised at various $\mathrm{Au}-\mathrm{Pt}$ atomic ratios, and were subsequently immobilised on $\mathrm{MgO}$ [33]. By performing the aerobic oxidation of glycerol at mild conditions ( 3 bar of $\mathrm{O}_{2}, 40-60{ }^{\circ} \mathrm{C}$ ) and without base, the efficient transformation of glycerol to glyceric acid was achieved at a selectivity of $80 \%$ and conversion levels of $43 \%$ (Fig. 4). Moreover, the general applicability of the novel $\mathrm{Au}-\mathrm{Pt} / \mathrm{MgO}$ catalysts was demonstrated by the efficient oxidation of ethylene and propylene diols. Extensive STEM-XEDS studies showed that the individual metal nanoparticles in the $\mathrm{Au}-\mathrm{Pt} / \mathrm{MgO}$ samples contain both $\mathrm{Au}$ and $\mathrm{Pt}$ metals, indicating the presence of Au-Pt alloy nanoparticles (Fig. 5). STEMHAADF analysis showed that the majority of Au-Pt particles exhibited a cuboctahedral structure, exposing a mixture of [111] and [200] facets.

\section{Case II. Selective oxidation of hydrocarbons}

The selective oxidation of hydrocarbons to useful chemical products is one of the greatest challenges in academia and

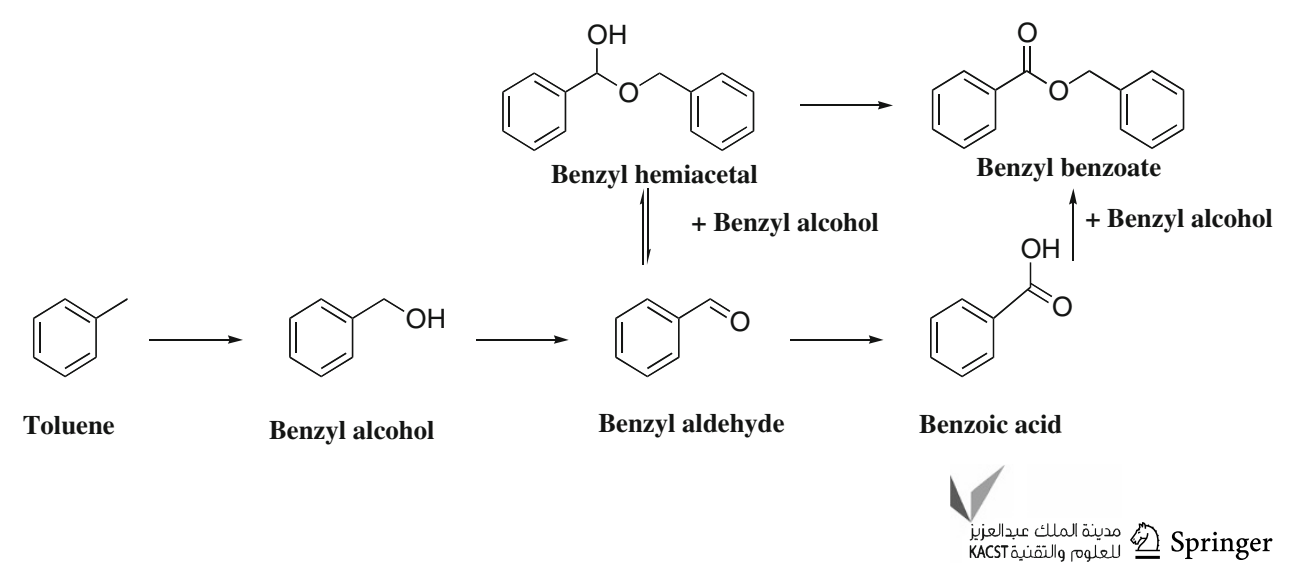


industry. However, given their low reactivity and high levels of stability, the activation of typically inert $\mathrm{C}-\mathrm{H}$ bonds often requires high reaction temperature, resulting in poor selectivity to the desired oxygenated organic products. Utilisation of catalysts that can lower the reaction temperature required for alkane activation, and thereby performing the catalytic transformation of hydrocarbons efficiently at lower temperatures, could result in an improved selectivity to oxygenated products. Taking into account that $\mathrm{Au}-\mathrm{Pd}$ supported nanoparticles synthesised by colloidal methods showed high catalytic efficiency for the oxidation of alcohols, polyols and hydrogen peroxide synthesis, we investigated the catalytic performance of these materials for the oxidation of toluene and methane at mild conditions. In the case of toluene, the efficient transformation of toluene to benzyl benzoate (90-95\% selectivity) was achieved at mild conditions $\left(120-160{ }^{\circ} \mathrm{C}, 10\right.$ bar of $\left.\mathrm{O}_{2}\right)$ using molecular oxygen or tertbutyl hydroperoxide as oxidant (Fig. 6) [34]. Mechanistic studies revealed that the oxidation proceeds via the initial formation of benzyl alcohol, which is rapidly oxidised to benzaldehyde. The formation of the analogous hemiacetal is followed by oxidation to the ester (Fig. 7). In subsequent studies, the effect of the oxidant was studied, and instead of molecular oxygen, tert-butyl hydroperoxide (TBHP) was used as the principal oxygen donor. High conversion of toluene at mild conditions $\left(80^{\circ} \mathrm{C}\right.$, atmospheric pressure) was achieved with benzoic acid being the major product (Fig. 8) [35]. Mechanistic studies were performed in order to elucidate the reaction mechanism, and especially the role of TBHP, and it was found for the first time that surface-bound oxygen-centred radicals play a role in activating toluene, as demonstrated by EPR studies.

The direct conversion of methane to methanol at mild conditions is one of the most important challenges that academia and industry face. Taking into account from previous studies that $\mathrm{H}_{2} \mathrm{O}_{2}$ or tert-butyl hydroperoxide has been used efficiently to oxidise methane, we thought that a hydroperoxide intermediate may be effective for the oxidation of methane. Therefore, the catalytic performance of supported $\mathrm{Au}-\mathrm{Pd}$ nanoparticles for the liquid-phase oxidation of methane was carried out using either $\mathrm{H}_{2} \mathrm{O}_{2}$, or in situ generated $\mathrm{H}_{2} \mathrm{O}_{2}$ from $\mathrm{H}_{2}$ and $\mathrm{O}_{2}$ as oxidant [36]. Using supported $\mathrm{Au}-\mathrm{Pd}$ nanoparticles synthesised by the impregnation method, high selectivity to oxygenated products (90\% including methyl hydroperoxide) and moderate selectivity to methanol $(50 \%)$ at mild reaction conditions $\left(50{ }^{\circ} \mathrm{C}\right)$ were achieved. The efficient oxidation of methane to methanol was possible even at $2{ }^{\circ} \mathrm{C}$, with an oxygenate selectivity of $93 \%$ found at these sub-ambient temperatures. Isotopic labelling studies were performed and confirmed that in the presence of the catalyst, all of the observed products were derived from methane (Fig. 9). EPR studies were also performed to investigate the nature of radical species that
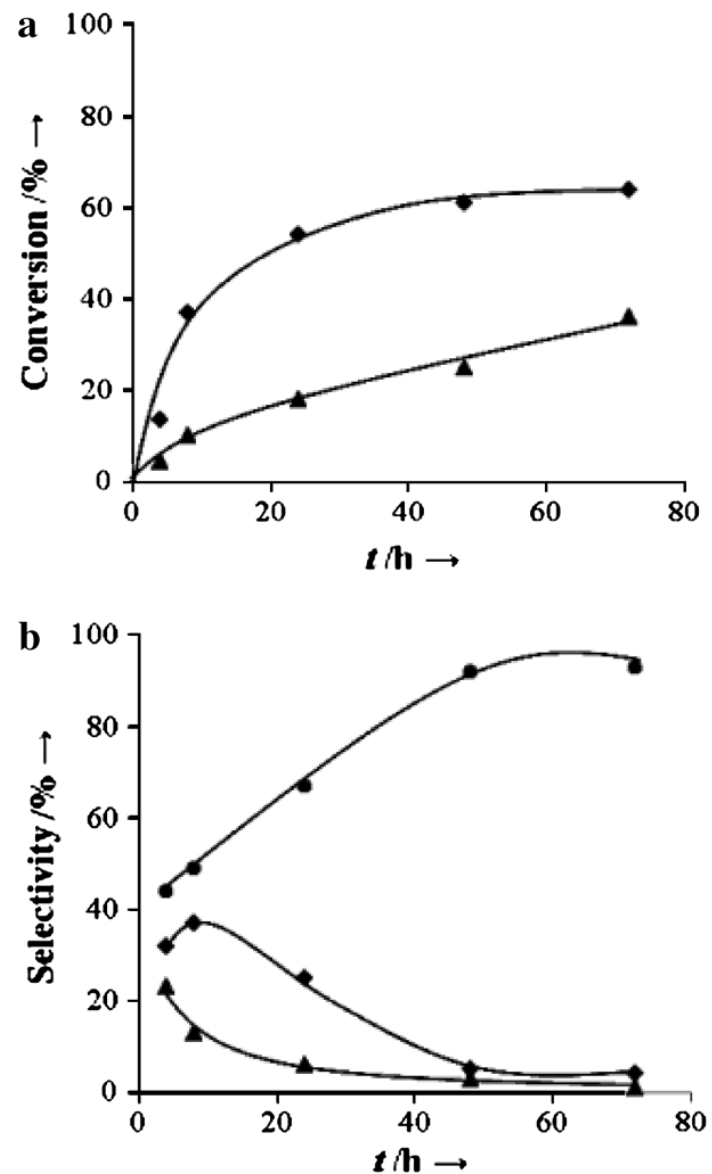

Fig. 8 Time-on-line data for the reaction of toluene. a Conversion of toluene (filled triangle) and TBHP (filled diamond). b Selectivities to benzaldehyde (filled diamond), benzyl alcohol (filled triangle) and benzoic acid (filled circle). Reaction conditions: molar ratio toluene/ $\mathrm{TBHP}=1, \quad 80 \quad 8 \mathrm{C}, \quad$ catalyst $\quad(0.2 \mathrm{~g}), \quad$ substrate/metal molar ratio $=6,500$. Reprinted with permission from reference [35]. Copyright (2012) Wiley-VCH

may produce during reaction. It was shown that both $\cdot \mathrm{CH}_{3}$ and $\cdot \mathrm{OH}$ radicals were formed during reaction, and that the methane oxidation mechanism for supported metal nanoparticles involves $\cdot \mathrm{CH}_{3}$ radical that can react either with surface-bound $\cdot \mathrm{OOH}$ to form $\mathrm{CH}_{3} \mathrm{OO} \cdot$, and eventually $\mathrm{CH}_{3} \mathrm{OH}$ and/or $\mathrm{H}_{2} \mathrm{CO}$, or with $\cdot \mathrm{OH}$ to produce $\mathrm{CH}_{3} \mathrm{OH}$ directly. At this stage, we believe that the major reaction pathway is the one via surface-bound $\cdot \mathrm{OOH}$ due to the observation of methyl hydroperoxide as the primary reaction product. Using the in situ generated $\mathrm{H}_{2} \mathrm{O}_{2}$ approach, a similar catalytic productivity was observed but with much higher methanol selectivity (70-80 \%).

\section{Concluding remarks}

Supported bimetallic (Au-Pd, Au-Pt) and trimetallic $(\mathrm{Au}-\mathrm{Pd}-\mathrm{Pt}$ ) nanoparticles are very effective catalysts for the "clean" and efficient oxidation of organic 
Fig. 9 a Time-on-line plot of methane oxidation with addition of $\mathrm{H}_{2} \mathrm{O}_{2}$ in the presence of a $1 \mathrm{wt} \% \mathrm{AuPd} / \mathrm{TiO}_{2 \mathrm{IW}}$ catalyst. Key: closed up triangle selectivity to methyl hydroperoxide, filled diamond selectivity to methanol, filled circle selectivity to carbon dioxide, $\mathbf{x}$ methane conversion. Reaction conditions: $\mathrm{P}_{(\mathrm{CH} 4)}$, 30.5 bar; $\left[\mathrm{H}_{2} \mathrm{O}_{2}\right], 0.5 \mathrm{M}$; T, $50{ }^{\circ} \mathrm{C}$; stirring rate, $1,500 \mathrm{rpm}$; catalyst mass, $10 \mathrm{mg}$. b ${ }^{1} \mathrm{H}-$ NMR spectrum of the reaction filtrate collected when using a solution initially spiked with

${ }^{13} \mathrm{CH}_{3} \mathrm{OOH}$ in a typical reaction using $5 \mathrm{wt} \% \mathrm{Au}-\mathrm{Pd} / \mathrm{TiO}_{2 \mathrm{w}}$ and pure ${ }^{12} \mathrm{CH}_{4}$. Reprinted with permission from reference [36]. Copyright (2013) Wiley-VCH
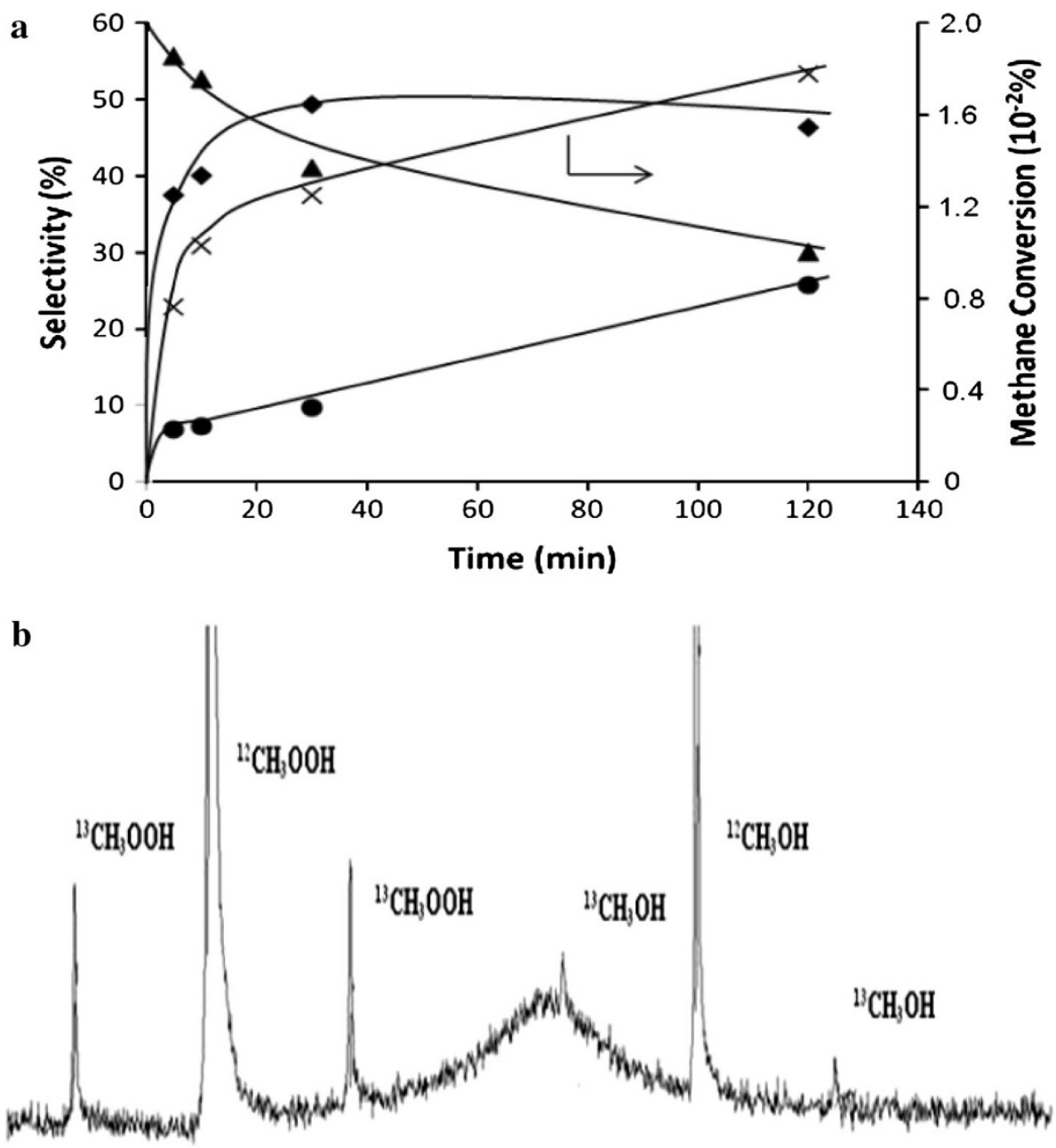

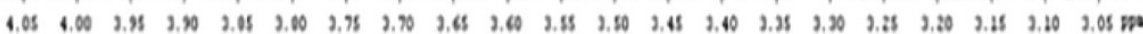

compounds (alcohols, polyols and alkanes) with molecular oxygen, hydrogen peroxide or alkyl hydroperoxides as "green" oxidants. A closer examination of the bimetallic/trimetallic catalysts reveals that it is important not only to control the particle size, but also to focus on the synthesis of structures consisting of an alloy or a core-shell structure, since electronic and geometric properties are affected in this manner. In the majority of the investigated reactions, it is generally accepted that the synthesis of nanoparticles of small particle size $(2-6 \mathrm{~nm})$ seems to be key for obtaining high catalytic activity. However, the particle size, shape and final morphology have all been shown to affect each oxidation process in a different way. In the future, control of the desired structure will play a major role in the development of new and more efficient catalysts, especially for industrial applications. Therefore, the main challenges that researchers will face in the near future are: (1) understanding the formation and the role of active sites, (2) developing more efficient, cheaper nanoparticles, particularly at lower metal loading, with prolonged catalytic life time, (3) scaling up nanoparticle synthesis, and (4) expanding the utilisation of Au-based and bimetallicbased catalysts in a larger variety of organic reactions. Finally, it is evident that the area of gold catalysis still remains an area of intense research, and is therefore a promising and growing area, with new materials and new reactions being regularly discovered and explored.

Open Access This article is distributed under the terms of the Creative Commons Attribution License which permits any use, distribution, and reproduction in any medium, provided the original author(s) and the source are credited.

\section{References}

1. Bond GC, Thompson DT (1999) Catalysis by gold. Catal Rev Sci Eng 41:319-388

2. Bond GC, Sermon PA, Webb G, Buchanan DA, Wells PB (1973) Hydrogenation over supported gold catalysts. J Chem Soc Chem Commun (13):444-445 
3. Hutchings GJ (1985) Vapor-phase hydrochlorination of acetylene-correlation of catalytic activity of supported metal chloride catalysts. J Catal 96:292-295

4. Haruta M, Kobayashi T, Sano H, Yamada N (1987) Novel gold catalysts for the oxidation of carbon-monoxide at a temperature far below $0{ }^{\circ} \mathrm{C}$. Chem Lett 16:405-408

5. Hashmi ASK, Hutchings GJ (2006) Gold catalysis. Angew Chem Int Ed 45:7896-7936

6. Della Pina C, Falletta E, Prati L, Rossi M (2008) Selective oxidation using gold. Chem Soc Rev 37:2077-2095

7. Herzing AA, Kiely CJ, Carley AF, Landon P, Hutchings GJ (2008) Identification of active gold nanoclusters on iron oxide supports for CO oxidation. Science 321:1331-1335

8. Xie XW, Li Y, Liu ZQ, Haruta M, Shen WJ (2009) Low-temperature oxidation of $\mathrm{CO}$ catalysed by $\mathrm{Co} 3 \mathrm{O} 4$ nanorods. Nature 458:746-749

9. Haruta M (2011) Spiers memorial lecture role of perimeter interfaces in catalysis by gold nanoparticles. Faraday Discuss 152:11-32

10. Yoshida H, Kuwauchi Y, Jinschek JR et al (2012) Visualizing gas molecules interacting with supported nanoparticulate catalysts at reaction conditions. Science 335:317-319

11. Akita T, Kohyama M, Haruta M (2013) Electron microscopy study of gold nanoparticles deposited on transition metal oxides. Acc Chem Res 46:1773-1782

12. Abad A, Concepcion P, Corma A, Garcia H (2005) A collaborative effect between gold and a support induces the selective oxidation of alcohols. Angew Chem Int Ed 44:4066-4069

13. Carrettin S, McMorn P, Johnston P, Griffin K, Hutchings GJ (2002) Selective oxidation of glycerol to glyceric acid using a gold catalyst in aqueous sodium hydroxide. Chem Commun 7:696-697

14. Sinha AK, Seelan S, Tsubota S, Haruta M (2004) A threedimensional mesoporous titanosilicate support for gold nanoparticles: vapor-phase epoxidation of propene with high conversion. Angew Chem Int Ed 43:1546-1548

15. Hughes MD, Xu YJ, Jenkins P et al (2005) Tunable gold catalysts for selective hydrocarbon oxidation under mild conditions. Nature 437:1132-1135

16. Nkosi B, Adams MD, Coville NJ, Hutchings GJ (1991) Hydrochlorination of acetylene using carbon-supported gold catalystsa study of catalyst reactivation. J Catal 128:378-386

17. Corma A, Serna P (2006) Chemoselective hydrogenation of nitro compounds with supported gold catalysts. Science 313:332-334

18. Landon P, Collier PJ, Papworth AJ, Kiely CJ, Hutchings GJ (2002) Direct formation of hydrogen peroxide from $\mathrm{H}-2 / \mathrm{O}-2$ using a gold catalyst. Chem Commun (18):2058-2059

19. Enache DI, Edwards JK, Landon P et al (2006) Solvent-free oxidation of primary alcohols to aldehydes using $\mathrm{Au}-\mathrm{Pd} / \mathrm{TiO} 2$ catalysts. Science 311:362-365

20. Edwards JK, Solsona BE, Landon P et al (2005) Direct synthesis of hydrogen peroxide from $\mathrm{H}-2$ and $\mathrm{O}-2$ using TiO2-supported $\mathrm{Au}-\mathrm{Pd}$ catalysts. J Catal 236:69-79

21. Edwards JK, Solsona B, En N et al (2009) Switching off hydrogen peroxide hydrogenation in the direct synthesis process. Science 323:1037-1041
22. Edwards JK, Ntainjua E, Carley AF, Herzing AA, Kiely CJ, Hutchings GJ (2009) Direct Synthesis of $\mathrm{H}_{2} \mathrm{O}_{2}$ from $\mathrm{H}-2$ and O-2 over Gold, Palladium, and Gold-Palladium Catalysts Supported on Acid-Pretreated TiO2. Angew Chem Int Ed 48:8512-8515

23. Mallat T, Baiker A (2004) Oxidation of alcohols with molecular oxygen on solid catalysts. Chem Rev 104:3037-3058

24. Dimitratos N, Lopez-Sanchez JA, Hutchings GJ (2012) Selective liquid phase oxidation with supported metal nanoparticles. Chem Sci 3:20-44

25. Daniel MC, Astruc D (2004) Gold nanoparticles: assembly, supramolecular chemistry, quantum-size-related properties, and applications toward biology, catalysis, and nanotechnology. Chem Rev 104:293-346

26. Lopez-Sanchez JA, Dimitratos N, Miedziak P et al (2008) Au-Pd supported nanocrystals prepared by a sol immobilisation technique as catalysts for selective chemical synthesis. Phys Chem Chem Phys 10:1921-1930

27. Dimitratos N, Lopez-Sanchez JA, Morgan D et al (2009) Solventfree oxidation of benzyl alcohol using Au-Pd catalysts prepared by sol immobilisation. Phys Chem Chem Phys 11:5142-5153

28. Tiruvalam RC, Pritchard JC, Dimitratos N et al (2011) Aberration corrected analytical electron microscopy studies of sol-immobilized $\mathrm{Au}$ plus $\mathrm{Pd}, \mathrm{Au}(\mathrm{Pd})$ and $\mathrm{Pd}(\mathrm{Au})$ catalysts used for benzyl alcohol oxidation and hydrogen peroxide production. Faraday Discuss 152:63-86

29. Meenakshisundaram S, Nowicka E, Miedziak PJ et al (2010) Oxidation of alcohols using supported gold and gold-palladium nanoparticles. Faraday Discuss 145:341-356

30. He Q, Miedziak PJ, Kesavan L et al (2013) Switching-off toluene formation in the solvent-free oxidation of benzyl alcohol using supported trimetallic Au-Pd-Pt nanoparticles. Faraday Discuss 162:365-378

31. Zhou CHC, Beltramini JN, Fan YX, Lu GQM (2008) Chemoselective catalytic conversion of glycerol as a biorenewable source to valuable commodity chemicals. Chem Soc Rev 37:527-549

32. Dimitratos N, Lopez-Sanchez JA, Anthonykutty JM et al (2009) Oxidation of glycerol using gold-palladium alloy-supported nanocrystals. Phys Chem Chem Phys 11:4952-4961

33. Brett GL, He Q, Hammond C et al (2011) Selective oxidation of glycerol by highly active bimetallic catalysts at ambient temperature under base-free conditions. Angew Chem Int Ed 50:10136-10139

34. Kesavan L, Tiruvalam R, Ab Rahim MH et al (2011) Solvent-free oxidation of primary carbon-hydrogen bonds in toluene using Au-Pd alloy nanoparticles. Science 331:195-199

35. bin Saiman MI, Brett GL, Tiruvalam R et al (2012) Involvement of surface-bound radicals in the oxidation of toluene using supported Au-Pd nanoparticles. Angew Chem Int Ed 51:5981-5985

36. Ab Rahim MH, Forde MM, Jenkins RL et al (2013) Oxidation of methane to methanol with hydrogen peroxide using supported gold-palladium alloy nanoparticles. Angew Chem Int Ed 52:1280-1284 